\title{
MiR-21 Regulates TNF- $\alpha$-Induced CD40 Expression via the SIRT1-NF-kB Pathway in Renal Inner Medullary Collecting Duct Cells
}

\author{
Qinqin Lin ${ }^{\mathrm{a}}$ Yuanwen Geng ${ }^{\mathrm{a}}$ Meng Zhao Shuaishuai Lin $^{\mathrm{b}}$ Qing Zhu ${ }^{\mathrm{a}}$ \\ Zhenjun Tianc \\ ${ }^{a}$ College of Physical Education, Yanshan University, Qinhuangdao, ${ }^{b}$ College of Education, Beijing Sport \\ University, Beijing, 'Institute of Sports and Exercise Biology, Shaanxi Normal University, Xi'an, China
}

\section{Key Words}

microRNA - SIRT1 - Cluster of differentiation 40 - Nuclear factor-kappa B - Inflammation • Renal inner medullary collecting duct (IMCD) cells

\begin{abstract}
Background/Aims: Recent studies have indicated that microRNA-21 (miR-21) is involved in the inflammatory response in relation to renal disease. Sirtuin1 (SIRT1) exerts renoprotective properties by counteracting inflammation. The activation of CD40 triggers inflammation that participates in renal inflammation and injury. The relationship between miR-21, SIRT1 and CD40, however, remains elusive. Methods: Immunohistochemistry, small-interfering RNA (siRNA) transfection, quantitative real-time PCR and western blotting were applied to assess the morphological, functional and molecular mechanisms in primary cultured renal inner medullary collecting duct (IMCD) cells. Results: TNF- $\alpha$ induced miR-21, CD40 and acetylated-NF-kBp65 (Ac-p65) expressions and reduced SIRT1 expression in IMCD cells. miR-21 mimics increased SIRT1 expression and attenuated Ac-p65 and CD40 expressions in TNF- $\alpha$-induced IMCD cells, and the corresponding changes were observed with a miR-21 inhibitor. SIRT1 overexpression or activation by SRT1720 diminished TNF- $\alpha$-induced CD40 and Ac-p65 expressions, which was reversed by SIRT1 siRNA or the inhibitors Ex527 and sirtinol and augmented by pretreatment with NF-KB siRNA. Further study found that the inhibitory effect of miR-21 on Ac-p65 and CD40 expressions was impeded by pretreatment with SIRT1 siRNA. Conclusion: The present study indicates that miR-21 inhibits TNF- $\alpha$-induced CD40 expression in IMCD cells via the SIRT1-NF-KB signalling pathway, which provides new insight in understanding the anti-inflammatory effect of miR-21.

\section{Introduction}

Sirtuin 1 (SIRT1), an $\mathrm{NAD}^{+}$-dependent class III histone/protein deacetylases, has been shown to play an important role in the regulation of inflammation associated with disease by suppressing the release of pro-inflammatory cytokines [1,2]. Recently, emerging evidences 


\section{Cellular Physiology Cell Physiol Biochem 2017;41:124-136

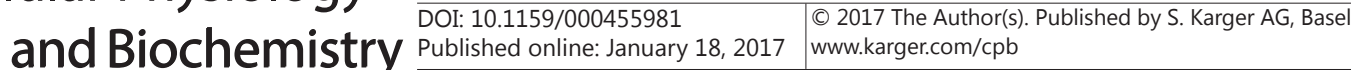

Lin et al.: miR-21 Regulates CD40 Expression via SIRT1-NF-kB Pathway

has suggested that SIRT1 is a novel target for prevention of kidney diseases [3-5]. It has been reported that kidney-specific overexpression of SIRT1 can maintain number and function of peroxisomes, eliminate renal reactive oxygen species levels, and protect against acute kidney injury (AKI) in vivo and in vitro [6]. Another study has revealed that SIRT1 deletion leads to increases of pro-inflammatory cytokines in the kidney tissues of rats with AKI [7]. Most studies have confirmed an important role of inflammation in the establishment of AKI associated with impaired urinary concentration and sodium and water reabsorption [8-10], and pro-inflammatory cytokines act in concert to promote inflammation and fluid imbalance promoting further kidney injury [11-13]. It is now well accepted that cluster of differentiation 40 (CD40), a marker of pro-inflammatory cytokines, plays a crucial role in the onset and maintenance of the inflammatory reaction [14]. The activation of CD40 has been reported to mediate pro-inflammatory events in renal tubule epithelial cells, which play a critical role with respect to water balance [15-17]. However, the effect of SIRT1 on the expression of CD40 in renal inner medullary collecting duct (IMCD) cells remain unclear. In addition, it is now well recognized that the anti-inflammatory properties of SIRT1 are closely related to its negative regulation of nuclear transcription factor (NF- $\kappa B$ ) [18]. Our previous studies and other studies have shown that NF- $\kappa B$ can regulate the gene expression of CD40 in adipocytes [19], endothelial cells [20], and macrophages [21]. However, whether the NF$\kappa \mathrm{B}$ pathway is involved in the modulatory effect of SIRT1 on CD40 expression in IMCD cells is not fully understood.

MicroRNAs (miRs) are a class of small noncoding RNA molecules that regulate gene expression by functioning as a post-transcriptional regulatory factor [22]. Emerging evidence has demonstrated that miRs play prominent roles in the inflammatory process in renal diseases [23-25]. For example, an abundance of miR-181a attenuated oxidized low density lipoprotein-induced CD40 expression, inhibited the secretion of the pro-inflammatory factors interleukin (IL)- 6 and tumour necrosis factor- $\alpha$ (TNF- $\alpha$ ), and up-regulated the antiinflammatory cytokine IL-10 in cultured bone marrow-derived dendritic cells (DCs) [26]. Moreover, up-regulation of miR-146a effectively decreased CD40 expression in CpG-induced DCs [27]. Among these miRs, more research has focused on miR-21 and its significant roles in proliferation, fibrosis, inflammation and apoptosis in different kidney diseases [28-30]. Recent research has confirmed that miR-21 may negatively regulate inflammatory processes. It has been shown that overexpression of miR-21 significantly abrogates the secretion of the inflammatory cytokine IL-6 and increases the level of anti-inflammatory cytokine IL10 in macrophages [31]. However, the relationship between miR-21and CD40 remains unknown. Therefore, this study was conducted to explore the possible effect of miR-21 on TNF- $\alpha$-induced CD40 expression in renal IMCD cells. Furthermore, although the previously described studies suggest that miRs are important regulators of SIRT1 expression [32, 33], little is known about the relationship between miR-21 and the SIRT1-dependent signalling pathway. Thus, we also investigated whether the SIRT1 pathway was involved in the effect of miR-21 on the expression of CD40 in renal IMCD cells.

\section{Materials and Methods}

\section{Reagents}

TNF- $\alpha$ (400-14) was obtained from PeproTech (Rocky Hill, NJ, USA). SRT1720 (S1129) and Ex527 (S1541) were obtained from Selleck Chemicals (Houston, TX, USA). Sirtinol (S7942) and pyrrolidine dithiocarbamate (PDTC) (P8765) were purchased from Sigma-Aldrich (St. Louis, MO, USA). Rabbit polyclonal anti-SIRT1, AQP2 and CD40 antibodies were provided by Santa Cruz (Santa Cruz, CA, USA). Rabbit polyclonal anti-NF- $\mathrm{KBp} 65$ and anti-GAPDH antibodies were ordered from Biosynthesis (Biosynthesis biotechnology Co., Ltd., Beijing, China). Rabbit polyclonal anti-acetyl-NF-кBp65 (lysine 310) (Ac-p65) antibody was obtained from Abcam (Cambridge, CA, USA). A BCA protein assay kit was purchased from Pierce (Rockford, IL, USA). All other reagents were purchased from Sigma-Aldrich (St. Louis, MO, USA). Lipofectamine ${ }^{\mathrm{TM}} 2000$ transfection reagent was purchased from Invitrogen (Life Technologies, NY, USA). 


\section{Cellular Physiology Cell Physiol Biochem 2017;41:124-136

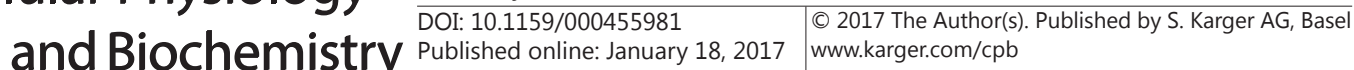

Lin et al.: miR-21 Regulates CD40 Expression via SIRT1-NF-KB Pathway

miR-21 mimics and inhibitors, small interfering RNAs (siRNAs) against SIRT1 and NF- $\kappa$ Bp65, as well as a negative control were synthesized by GenePharma (GenePharma Co., Ltd., Shanghai, China) (http://www.genepharma.com) with the following sequences: miR-21 mimics forward 5'-UAGCUUAUCAGACUGAUGUUGA-3'and reverse 5'-AACAUCAGUCUGAUA AGCUAUU-3'; miR-21 inhibitor 5'-UCAACAUCAGUCUGAUAACUA-3'; SIRT1 siRNA forward 5'-CCCUGUAAAGCUUUCAGAATT-3' and reverse 5'-UUCUGAAAGCUUUACAG GGTT-3'; NF-кBp65 siRNA forward 5'-GGAGUACCCUGAAGCUAUATT-3' and reverse 5'-UAUAGCUUCAGGGUACUCCTT-3'; Negative control forward 5'-UUCUCCGAACGUGUCA CGUTT-3' and reverse 5'-ACGUGACACGUUCGGAGAATT-3'.

Primary culture of rat kidney IMCD cells

Primary cultures enriched in IMCD cells were prepared from male Sprague-Dawley rats (120-140 g body wt), as previously described [34]. All experimental protocols were approved by the Review Committee for the Use of Human or Animal Subjects of Yanshan University. Both kidneys were rapidly removed from rats under light diethyl ether inhalation anaesthesia. After kidney excision, the renal inner medullas including papilla were rapidly removed, cut into small pieces, and digested in phosphate-buffered saline (PBS) containing $1 \mathrm{mg} / \mathrm{ml}$ hyaluronidase and $2.2 \mathrm{mg} / \mathrm{ml}$ collagenase type CLS-II at $37^{\circ} \mathrm{C}$ under continuous agitation for 90 min. After centrifugation, the pellet was washed in prewarmed culture medium (Dulbecco's modified Eagle's medium containing $100 \mathrm{mM} \mathrm{NaCl}, 100 \mathrm{mM}$ urea, 1\% non-essential amino acids, 1\% ultroser, $500 \mu \mathrm{M}$ DBcAMP, $20 \mathrm{U} / \mathrm{ml}$ nystatin and $0.25 \mu \mathrm{g} / \mathrm{ml}$ gentamicin). The resulting IMCD cell suspension was seeded in $60 \mathrm{~mm}$ culture dish and incubated with treatments described in the Results section.

\section{Immunofluorescence staining}

IMCD cells were fixed in 10\% paraformaldehyde-PBS for $30 \mathrm{~min}$. The fixed cell membrane was fenestrated with $0.5 \%$ Triton X-100 in PBS for $5 \mathrm{~min}$, and then blocked with 5\% goat serum for $30 \mathrm{~min}$. The cells were incubated with polyclonal anti-rabbit AQP2 antibody $\left(1: 100\right.$ dilutions) overnight at $4^{\circ} \mathrm{C}$, and then incubated with a FITC-conjugated goat anti-rabbit IgG polyclonal antibody (1:100 dilutions) for $2 \mathrm{~h}$. After the nuclei were stained with 4'-6-diamidino-2-phenylindole (DAPI) dye (1:800 dilutions) for 15 min, the stained cells were investigated using confocal laser scanning microscopy (Nikon, Tokyo, Japan).

\section{Immunohistochemical examination}

IMCD cells were fixed in 10\% paraformaldehyde in PBS for 30 min and then washed three times with PBS. The fixed cells were permeabilized with $0.5 \%$ Triton X-100 in PBS for 5 min at room temperature and washed three times with PBS. Endogenous peroxidase activity was blocked by treating the sections with $3 \%$ hydrogen peroxide in phosphate-buffered saline for $10 \mathrm{~min}$. The cells were then blocked with $5 \%$ bovine serum albumin (BSA) in PBS at room temperature for $30 \mathrm{~min}$. To detect CD40 protein expression, a rabbit anti-CD40 polyclonal antibody (1:100 dilutions in PBS) was incubated with cells overnight at $4^{\circ} \mathrm{C}$. After being washed three times with PBS, the cells were incubated with secondary antibodies for 30 min at room temperature. Finally, the cells were developed by applying diaminobenzidine as a chromogen, followed by counterstaining with haematoxylin. The cells that had not been incubated with primary antibodies served as negative controls. The optical density of the scanned images was computerized using a digital image analyser by IMAGE-PRO PLUS 6.0 (Media Cybernetics).

\section{Transient transfection}

The recombinant plasmid pcDNA3.1(+)-SIRT1 was provided by $\mathrm{Dr}$. Bu. The recombinant plasmid pcDNA3.1(+)-SIRT1 was confirmed by restriction enzyme analysis and DNA sequencing. For transfection, IMCD cells were plated on 6-well plates. For the SIRT1 overexpression experiments, the cells were transiently transfected for $48 \mathrm{~h}$ with pcDNA3.1(+)-SIRT1 or pcDNA3.1(+) using Lipofectamine 2000, according to the manufacturer's protocol. After $48 \mathrm{~h}$, transfected cells were harvested and analysed by western blotting to detect the level of SIRT1 expression.

\section{RNA interference}

The cells were transfected with $20 \mu \mathrm{M}$ synthesized siRNA targeting rat SIRT1 and NF- $\kappa$ Bp65, and scrambled siRNA was used as a negative control (NC siRNA). The siRNA and Lipofectamine 2000 were separately diluted in serum-free DMEM and incubated for $5 \mathrm{~min}$ at room temperature. Then the two 


\section{Cellular Physiology Cell Physiol Biochem 2017;41:124-136

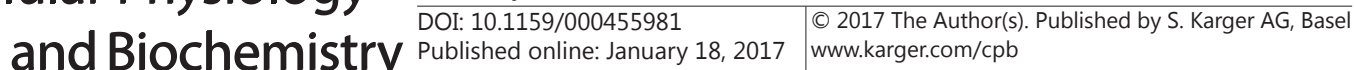

Lin et al.: miR-21 Regulates CD40 Expression via SIRT1-NF-KB Pathway

solutions were gently mixed and incubated for $20 \mathrm{~min}$, followed by addition to the cells. The IMCD cells were transfected with siRNA Lipofectamine complexes and incubated for $48 \mathrm{~h}$ at $37^{\circ} \mathrm{C}$ in a $\mathrm{CO}_{2}$ incubator, and then were used in the experiments.

For overexpression or knockdown of miR-21, cells were transfected with either $100 \mathrm{nM}$ miR-21 mimics, inhibitors or miR-control (NC mimics and inhibitor). All miRNAs were transfected into IMCD cells with Lipofectamine 2000 in accordance with the manufacturer's procedure. After $48 \mathrm{~h}$ of incubation, the cells were processed for further analysis.

\section{Western blot}

Protein samples were separated by 10 12\% SDS-PAGE gels and transferred to polyvinylidene difluoride (PVDF) membranes (Millipore). The membranes were blocked in 5\% non-fat dry milk for $1 \mathrm{~h}$. After blocking, the following primary antibodies were utilized: rabbit polyclonal anti-SIRT1 (1:400 dilutions); anti-CD40 (1:500 dilutions); anti-Ac-p65 (1:500 dilutions); anti-NF-кBp65 (1:800 dilutions), and anti-GAPDH (1:5000 dilutions). The membranes were incubated with horseradish peroxidase-conjugated secondary antibodies (1:10000 dilutions). Protein bands were subsequently detected with enhanced chemiluminescence (ECL System; Millipore), and sections were exposed to X-ray film (Kodak). GAPDH was used as an internal control.

\section{Quantitative real-time polymerase chain reaction (RT-qPCR)}

Total RNA was extracted from IMCD cells using TRIzol reagent (Life Technologies, Foster, CA, USA). Complementary DNA was synthesized using a PrimeScript RT reagent kit (Perfect RealTime; TaKaRa). The RT-qPCR was performed using SYBR Green PCR master mix (TaKaRa) on a Bio-Rad CFX connect real-time system (Bio-Rad, Hercules, CA, USA), following the manufacturer's instructions. The samples were run in triplicate. The following primers were used for amplification: SIRT1 forward 5'-CAGTTCCAGCCATCTCTGTG3' and reverse 5'-GCAAC CTGCTCCAAGGTATC-3'; CD40 forward 5'-TAGCCACTGCACAGCTCTTG-3' and reverse 5'-GAAGCCCTTGATTGAGTTCG-3'; GAPDH forward 5'-ACAGCAACAGGGTGGTGGAC-3'and reverse 5'-TTTGAGGGTGCAGCGAACTT-3'. GAPDH was used as an endogenous control. Quantification of relative gene expression was calculated by the comparative Ct method $\left(2^{-\Delta \Delta C t}\right)$ as described by the manufacturer. Data were normalized to rat GAPDH mRNA levels. Three independent experiments were performed to study mRNA levels.

Expression levels of mature miR-21 were detected using a PrimeScript ${ }^{\mathrm{TM}}$ miRNA qPCR Kit (TaKaRa) according to the manufacturer's instructions. The samples were run in triplicate. U6 was used as an endogenous control. The miR-21 and U6 primers were obtained from TaKaRa. Quantification of relative gene expression was calculated by the comparative Ct method $\left(2^{-\Delta \Delta C t}\right)$ as described by the manufacturer. Data were normalized to rat U6 levels. Three independent experiments were performed to study miRNA levels.

\section{Statistical analyses}

All values in the results are expressed as the mean \pm SD. Statistical significance between means was analysed by one-way ANOVA followed by a post hoc test. A value of $P<0.05$ was considered statistically significant.

\section{Results}

TNF- $\alpha$ increases CD40 expression in IMCD cells

It is well known that aquaporins (AQPs; a family of water channel proteins), especially $\mathrm{AQP2}$, play major role in water reabsorption in renal IMCD cells. To determine whether the IMCD cells are functional, labelled AQP2 was examined in IMCD cells after short-term 1-desamino-8-D-arginine vasopressin (dDAVP) treatment. Our results revealed that AQP2 was largely dispersed within the cytoplasm of IMCD cells. Interestingly, treatment with 100 nM AVP for 30 min clearly increased the AQP2 expression in the plasma membrane and decreased it in the cytoplasm (Fig. 1A), indicating that the IMCD cells were correctly cultured.

To determine whether CD40 is expressed in IMCD cells, immunohistochemical staining was performed. The results showed that CD40 was dispersed in the cytoplasm of primary 


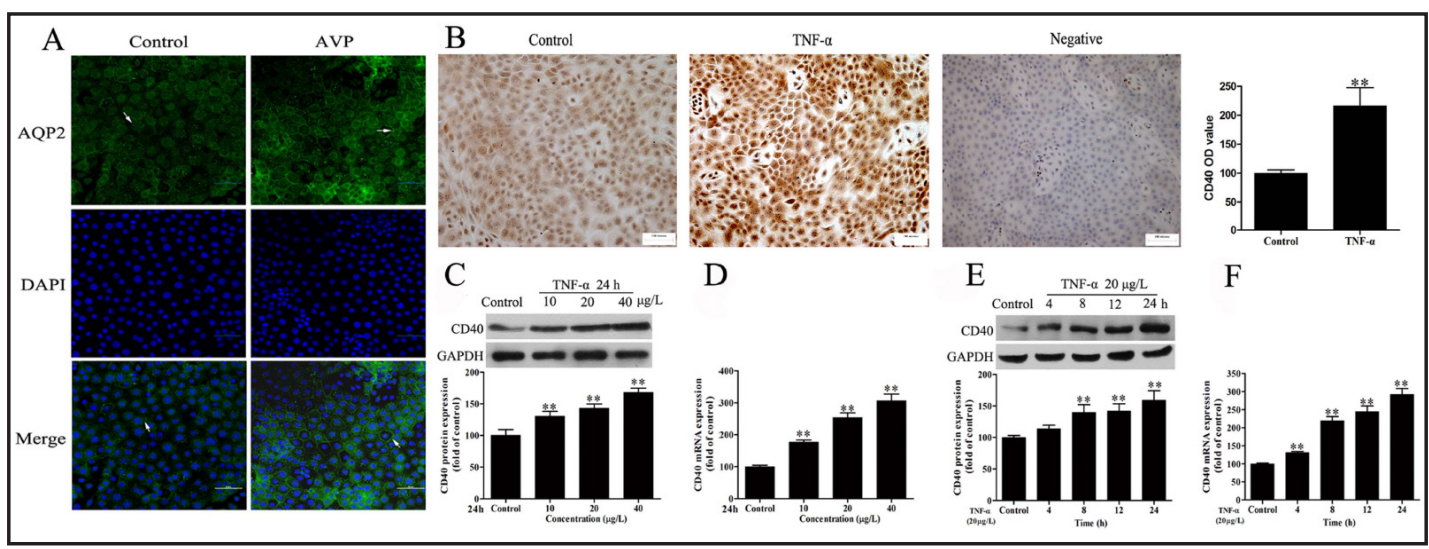

Fig. 1. TNF- $\alpha$ increases CD40 expression in IMCD cells. (A) Immunofluorescence microscopy of aquaporin 2 (AQP2) in primary IMCD cells. The IMCD cells were treated with $100 \mathrm{nM}$ AVP for $30 \mathrm{~min}$, and immunofluorescence staining was performed. AQP2 was stained with anti-AQP2 antibody (coloured in green/indicated by the arrow). The nuclear protein was stained with DAPI (blue). Merge represents the combined image of AQP2 fluorescence and nuclear staining. Images of cells were generated on a microscope at 200× magnification, bar=50 $\mu \mathrm{m}$. (B) Immunohistochemistry of CD40 in primary IMCD cells. CD40-positive cells are shown by a deep brown colour. Images of cells were generated on a microscope at $200 \times$ magnification, bar $=100 \mu \mathrm{m}$. (C and D) The cells were treated with different concentrations of TNF- $\alpha$ (10, 20 and $40 \mu \mathrm{g} / \mathrm{L}$ ) for $24 \mathrm{~h}$, and the protein and mRNA expression of CD40 was examined by western blotting and RT-qPCR, respectively. (E and F) The cells were stimulated with TNF- $\alpha(20 \mu \mathrm{g} / \mathrm{L})$ for the indicated time, and the protein and mRNA expression of CD40 was examined by western blotting and RT-qPCR, respectively. ${ }^{* *} P<0.01$ vs. control group. The results are expressed as the means \pm SD from triplicate experiments.

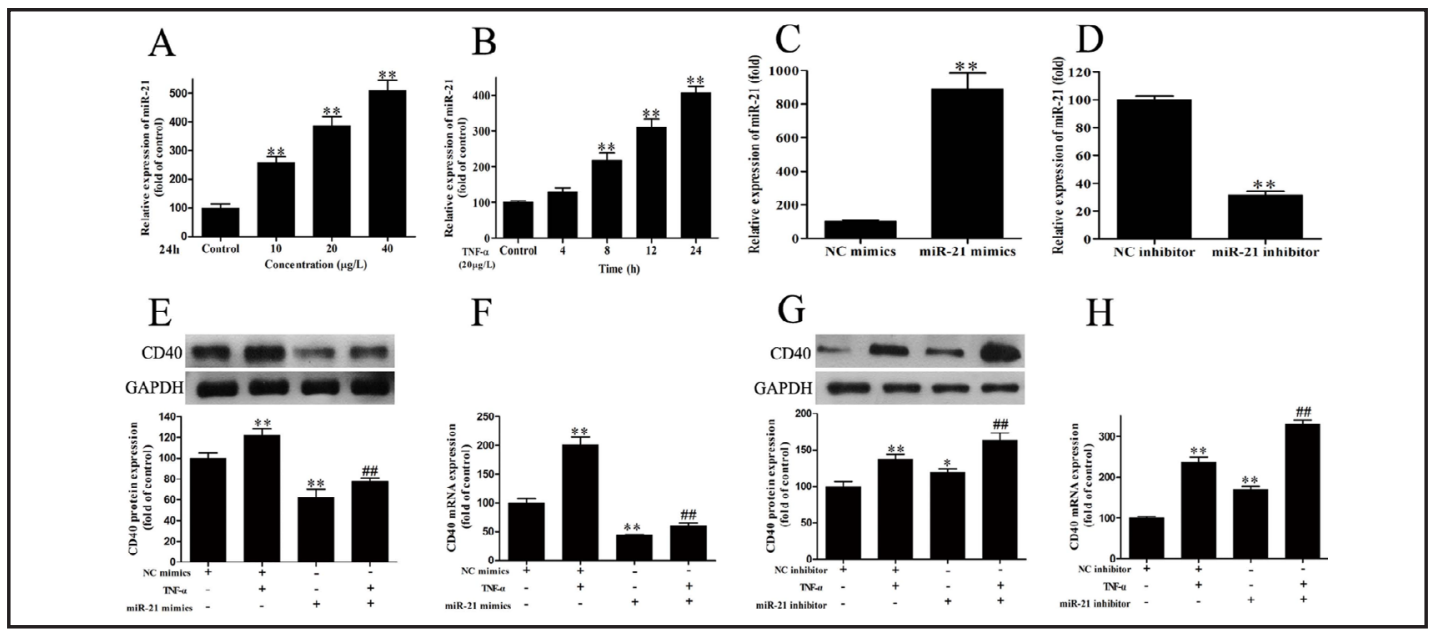

Fig. 2. miR-21 regulates TNF- $\alpha$-induced CD40 expression in IMCD cells. (A) The cells were treated with different concentrations of TNF- $\alpha(10,20$ and $40 \mu \mathrm{g} / \mathrm{L})$ for $24 \mathrm{~h}$, and the expression level of miR-21 was determined by RT-qPCR. ${ }^{* *} P<0.01$ vs. control group. (B) The cells were stimulated with TNF- $\alpha(20 \mu \mathrm{g} / \mathrm{L})$ for the indicated time, and the expression level of miR-21 was determined by RT-qPCR. ${ }^{* *} P<0.01$ vs. control group. (C) IMCD cells were transfected with miR-21 mimics or negative control mimics (NC mimics) for 48 $h$, and the expression level of miR-21 was detected by RT-qPCR. ${ }^{* *} P<0.01$ vs. NC mimics group. (D) IMCD cells were transfected with miR-21 inhibitor or negative control inhibitor (NC inhibitor) for $48 \mathrm{~h}$, and the expression level of miR-21 was detected by RT-qPCR. ${ }^{* *} P<0.01$ vs. NC inhibitor group. (E and F) The IMCD cells transfected with miR-21 mimics were treated with TNF- $\alpha(20 \mu \mathrm{g} / \mathrm{L})$ for $24 \mathrm{~h}$, and the protein and mRNA expression of CD40 was examined by western blotting and RT-qPCR, respectively. ${ }^{* *} P<0.01$ vs. NC mimics group; ${ }^{\# \#} P<0.01$ vs. NC mimics + TNF- $\alpha$ group. (G and H) The IMCD cells transfected with miR-21 inhibitor were treated with TNF- $\alpha(20 \mu \mathrm{g} / \mathrm{L})$ for $24 \mathrm{~h}$, and the protein and mRNA expression of CD40 was examined by western blotting and RT-qPCR, respectively. ${ }^{*} P<0.05$ and ${ }^{* *} P<0.01$ vs. NC inhibitor group; ${ }^{\# \#} P<0.01$ vs. NC inhibitor + TNF- $\alpha$ group. The results are expressed as the means \pm SD from triplicate experiments.

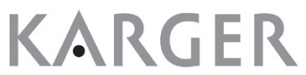




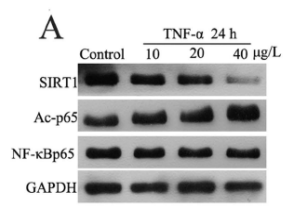

$\mathrm{F}$
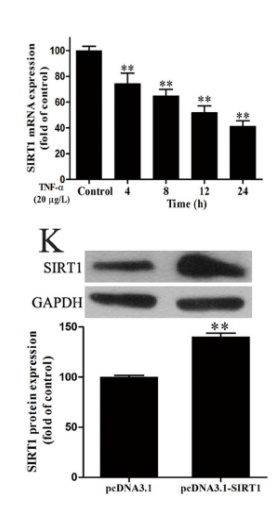
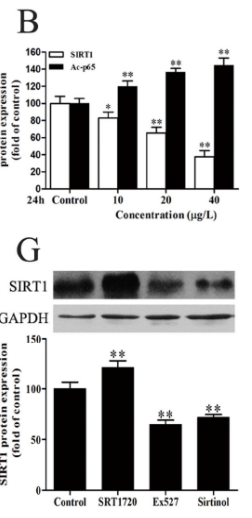

L

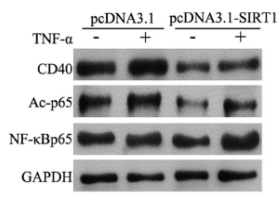

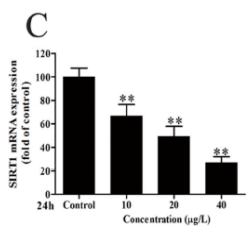

$\mathrm{H}$

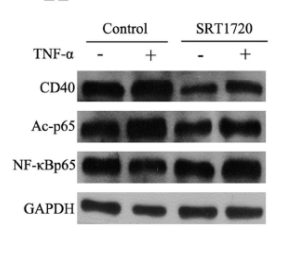

M

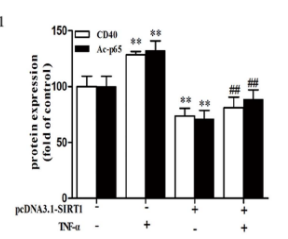

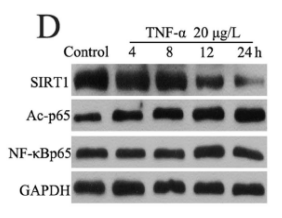

I

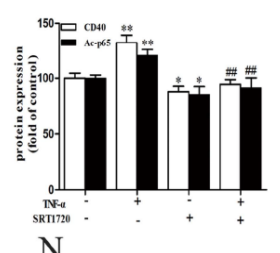

$\mathrm{N}$

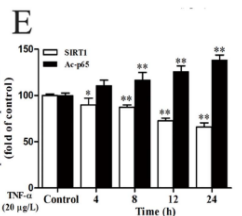

$\mathbf{J}$
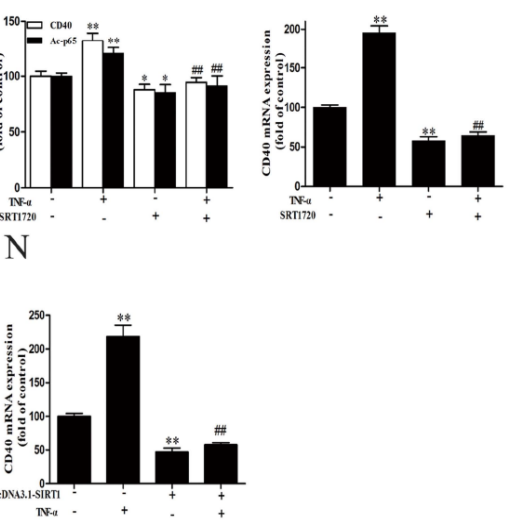

Fig. 3. SIRT1 inhibits TNF- $\alpha$-induced CD40 expression in IMCD cells. (A-C) The cells were treated with various concentrations of TNF- $\alpha(10,20$ and $40 \mu \mathrm{g} / \mathrm{L})$ for $24 \mathrm{~h}$, and the expression of SIRT1 mRNA and protein and acetyl-NF- $\kappa$ Bp65 (Ac-p65) protein was examined. ${ }^{*} P<0.05$ and ${ }^{* *} P<0.01$ vs. control group. (D-F) The cells were stimulated with TNF- $\alpha(20 \mu \mathrm{g} / \mathrm{L})$ for the indicated time, and the expression of SIRT1 mRNA and protein and Ac-p65 protein was examined. ${ }^{*} P<0.05$ and ${ }^{* *} P<0.01$ vs. control group. (G) The cells were treated with SRT1720 $(10 \mu \mathrm{M})$, Ex527 $(1 \mu \mathrm{M})$ or sirtinol $(10 \mu \mathrm{M})$ for $24 \mathrm{~h}$, and the expression of SIRT1 was examined by western blotting. ${ }^{* *} P<0.01$ vs. control group. (H-J) The cells were pretreated with SRT1720 $(10 \mu \mathrm{M})$ for $1 \mathrm{~h}$ prior to stimulation with TNF- $\alpha(20 \mu \mathrm{g} / \mathrm{L})$ for $24 \mathrm{~h}$, and the expression of CD40 mRNA and protein and Ac-p65 protein was examined. ${ }^{*} P<0.05$ and ${ }^{* *} P<0.01$ vs. control group; ${ }^{\# \# ~} P<0.01$ vs. TNF- $\alpha$ group. (K) IMCD cells were transfected with pcDNA3.1(+)-SIRT1 for $48 \mathrm{~h}$, and the protein expression of SIRT1 was detected by western blotting. ${ }^{* *} P<0.01$ vs. pcDNA3.1 group. (L-N) SIRT1-overexpressing cells were stimulated with TNF- $\alpha(20 \mu \mathrm{g} / \mathrm{L})$ for $24 \mathrm{~h}$, and the expression of CD40 mRNA and protein and Ac-p65 protein was examined. ${ }^{* *} P<0.01$ vs. pcDNA3.1 group; ${ }^{\# \#} P<0.01$ vs. pcDNA3.1 + TNF- $\alpha$ group. The results are expressed as the means \pm SD from triplicate experiments.

cultured IMCD cells in the absence of TNF- $\alpha$ stimulation. Moreover, treatment with $20 \mu \mathrm{g} / \mathrm{L}$ TNF- $\alpha$ for $24 \mathrm{~h}$ was associated with an increase in CD40 immunohistochemical staining of the cytoplasm. Image analysis further demonstrated that the optical density of CD40 was significantly higher in the TNF- $\alpha$ group compared with the control group (Fig. 1B). To further investigate whether CD40 expression could be regulated by TNF- $\alpha$ in IMCD cells, western blotting and RT-qPCR were used. The results revealed that treatment of IMCD cells with TNF- $\alpha(10,20$ and $40 \mu \mathrm{g} / \mathrm{L})$ for $24 \mathrm{~h}$ significantly increased the expression of CD $40 \mathrm{mRNA}$ and protein in a concentration-dependent manner (Fig. 1C and D). To further investigate the effect of TNF- $\alpha$ within various time points, the cells were stimulated with TNF- $\alpha(20 \mu \mathrm{g} / \mathrm{L})$ for 4, 8, 12 and $24 \mathrm{~h}$. The results showed that TNF- $\alpha$ increased the expression of CD40 mRNA and protein in a time-dependent manner (Fig. 1E and F).

miR-21 regulates TNF- $\alpha$-induced CD40 expression in IMCD cells

To explore whether TNF- $\alpha$ influenced miR-21 expression, IMCD cells were treated with different concentrations of TNF- $\alpha(10,20$ and $40 \mu \mathrm{g} / \mathrm{L})$ for $24 \mathrm{~h}$, and the expression level of miR-21 was determined using RT-qPCR. We found that treatment of cells with TNF- $\alpha$ significantly increased the expression level of miR-21in a concentration-dependent manner (Fig. 2A). We further studied the time course of the miR-21 expression level in IMCD cells 


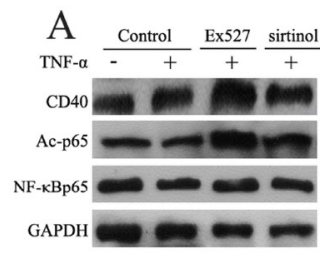

$\mathrm{D}$

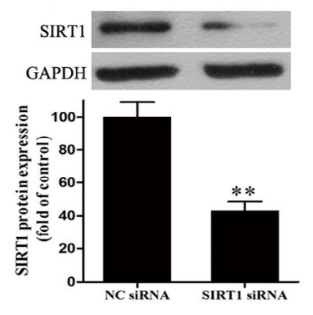

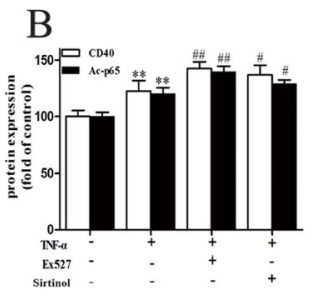

$\mathrm{E}$

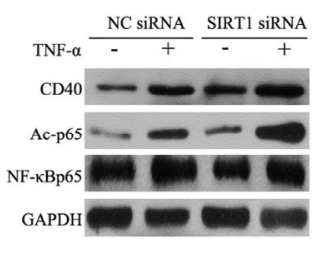

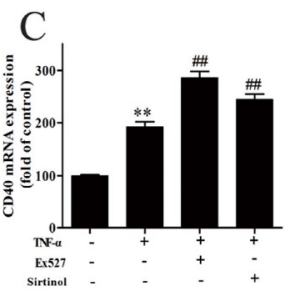

$\mathrm{F}$

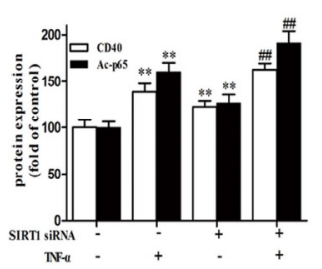

G

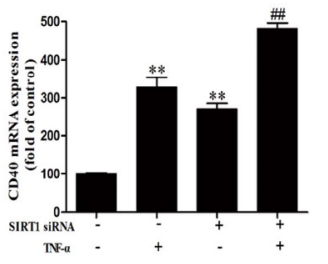

Fig. 4. Inhibition of SIRT1 increases TNF- $\alpha$-induced CD40 expression in IMCD cells. (A-C) The cells were pretreated with Ex527 $(1 \mu \mathrm{M})$ or sirtinol $(10 \mu \mathrm{M})$ for $1 \mathrm{~h}$ prior to stimulation with TNF- $\alpha(20 \mu \mathrm{g} / \mathrm{L})$ for 24 $\mathrm{h}$, and the expression of CD40 mRNA and protein and Ac-p65 protein was examined. ${ }^{* *} P<0.01$ vs. control group; ${ }^{\#} P<0.05$ and ${ }^{\# \#} P<0.01$ vs. TNF- $\alpha$ group. (D) IMCD cells were transfected with negative control siRNA (NC siRNA) or SIRT1 siRNA for $48 \mathrm{~h}$, and the protein expression of SIRT1 was detected by western blotting. ${ }^{* *} P<0.01$ vs. NC siRNA group. (E-G) The SIRT1-knockdown cells were stimulated with TNF- $\alpha(20 \mu \mathrm{g} / \mathrm{L})$ for $24 \mathrm{~h}$, and the expression of CD40 mRNA and protein and Ac-p65 protein was examined. $* * P<0.01$ vs. NC siRNA group; ${ }^{\# \#} P<0.01$ vs. NC siRNA + TNF- $\alpha$ group. The results are expressed as the means \pm SD from triplicate experiments.

by treating with TNF- $\alpha(20 \mu \mathrm{g} / \mathrm{L})$ for $4,8,12$ and $24 \mathrm{~h}$. An obvious up-regulation of miR-21 expression levels was observed at $8 \mathrm{~h}$ post TNF- $\alpha$ stimulation. Simultaneously, treatment with inchmeal increased times of TNF- $\alpha$ stimulation, the expression levels of miR-21 were gradually up-regulated, indicating that TNF- $\alpha$ triggered a time-dependent increase in the expression level of miR-21 in IMCD cells (Fig. 2B). Taken together, these results confirmed that TNF- $\alpha$ could trigger expression level of miR-21 in IMCD cells in a concentration- and time-dependent manner

To investigate the effect of miR-21 on the expression of CD40 induced by TNF- $\alpha$ in IMCD cells, we overexpressed and silenced the expression of miR-21 in IMCD cells. After transfection with miR-21 mimics for $48 \mathrm{~h}$, a significant increase in the miR-21 expression level was observed in IMCD cells compared with the NC mimics group (Fig. 2C). Moreover, an inhibitor of miR-21 strikingly reduced the expression level of miR-21 in IMCD cells (Fig. 2D). Then, the IMCD cells transfected with miR-21 mimics or inhibitor were treated with TNF- $\alpha$ $(20 \mu \mathrm{g} / \mathrm{L})$ for $24 \mathrm{~h}$, and the mRNA and protein expression of CD40 was measured. The results showed that overexpression of miR-21 obviously decreased the expression of CD40 mRNA and protein in IMCD cells, compared with the TNF- $\alpha$ group (Fig. 2E and F). Knockdown of miR-21 remarkably increased the expression of CD40 mRNA and protein compared with TNF- $\alpha$ group (Fig. $2 \mathrm{G}$ and $\mathrm{H}$ ), suggesting that miR-21 might regulate the expression of CD40 induced by TNF- $\alpha$ in IMCD cells.

SIRT1 inhibits TNF- $\alpha$-induced CD40 expression via NF- $\kappa B$ in IMCD cells

The IMCD cells were treated with different concentrations of TNF- $\alpha(10,20$ and $40 \mu \mathrm{g} / \mathrm{L})$ for $24 \mathrm{~h}$, and the expression of SIRT1 and Ac-p65 was determined. The results showed that treatment of IMCD cells with TNF- $\alpha$ significantly decreased the expression of SIRT1 mRNA and protein and increased the expression of Ac-p65 protein in a concentration-dependent manner (Fig. 3A-C). We further studied the time courses of SIRT1 and Ac-p65 expression in 


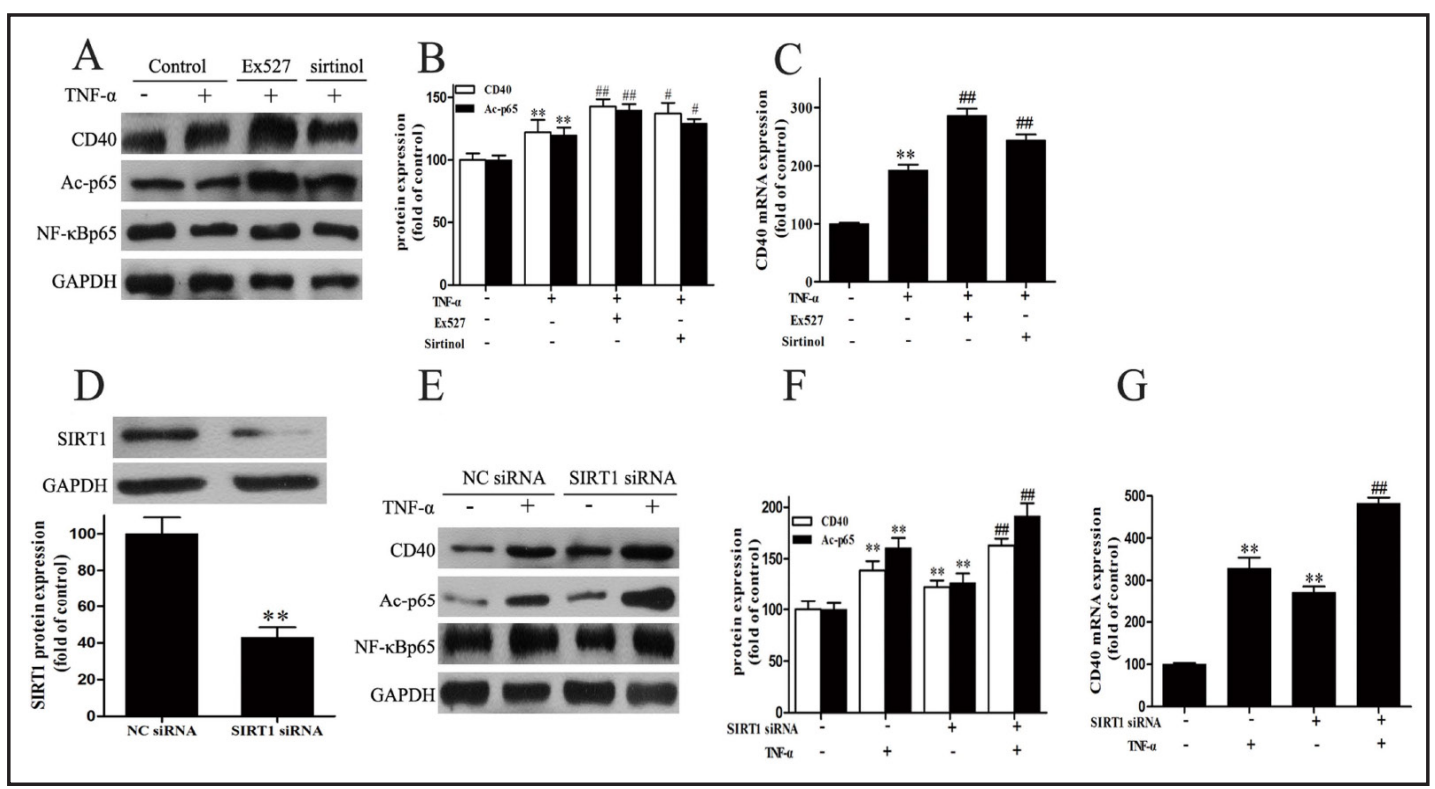

Fig. 5. NF- $\kappa B$ promotes TNF- $\alpha$-induced CD40 expression in IMCD cells. (A and B) The IMCD cells were pretreated with PDTC $(10 \mu \mathrm{M})$ for $1 \mathrm{~h}$ prior to stimulation with TNF- $\alpha(20 \mu \mathrm{g} / \mathrm{L})$ for $24 \mathrm{~h}$, and the expression of CD40 mRNA and protein and Ac-p65 protein was examined. ${ }^{*} P<0.01$ vs. control group; ${ }^{\# \# ~} P<0.01$ vs. TNF- $\alpha$ group. (C) The IMCD cells were transfected with negative control siRNA (NC siRNA) or NF- $\kappa B p 65$ siRNA for $48 \mathrm{~h}$. The protein expression of Ac-p65 was detected by western blotting. ${ }^{* *} P<0.01$ vs. NC siRNA group. (D and E) The NF- $\kappa B p 65-k n o c k d o w n$ cells were stimulated with TNF- $\alpha(20 \mu \mathrm{g} / \mathrm{L})$ for $24 \mathrm{~h}$, and the protein and mRNA expression of CD40 was examined by western blotting and real-time PCR, respectively. ${ }^{* *} P<0.01$ vs. NC siRNA group; ${ }^{\# \#} P<0.01$ vs. NC siRNA + TNF- $\alpha$ group. (F) The NF- $\kappa B p 65$ siRNA cells were transfected with pcDNA3.1(+)-SIRT1 for $48 \mathrm{~h}$, and subsequently treated with TNF- $\alpha(20 \mu \mathrm{g} / \mathrm{L})$ for $24 \mathrm{~h}$, and the protein expression of CD40 was examined by western blotting. ${ }^{\# \# ~} P<0.01$ vs. TNF- $\alpha$ group; ${ }^{\ddagger \neq} P<0.01$ vs. NF- $\kappa B p 65$ siRNA + pcDNA3.1(+)-SIRT1 + TNF- $\alpha$ group. The results are expressed as the means \pm SD from triplicate experiments.

IMCD cells by treating with TNF- $\alpha(20 \mu \mathrm{g} / \mathrm{L})$ for $4,8,12$ and $24 \mathrm{~h}$. The results showed that TNF- $\alpha$ inhibited the expression of SIRT 1 mRNA and protein and increased the expression of Ac-p65 protein in a time-dependent manner (Fig. 3D-F).

To identify the role of SIRT1 in the expression of Ac-p65 and CD40 in TNF- $\alpha$-induced IMCD cells, we overexpressed SIRT1 in IMCD cells. After treatment with the SIRT1 activator SRT1720 $(10 \mu \mathrm{M})$ or the pcDNA3.1(+)-SIRT1 plasmid, increases in SIRT1 protein were observed in IMCD cells, compared with the control groups (Fig. 3G and K). Then, the IMCD cells were pretreated with SRT1720 for $1 \mathrm{~h}$ or pcDNA3.1(+)-SIRT1 for $48 \mathrm{~h}$ prior to stimulation with TNF- $\alpha(20 \mu \mathrm{g} / \mathrm{L})$ for $24 \mathrm{~h}$. The results showed that SRT1720 significantly reduced the mRNA and protein expression of CD 40 induced by TNF- $\alpha$ in IMCD cells as well as the expression of Ac-p65 (Fig. 3H-J). Overexpression of SIRT1 further supported the above results by inducing decreased expression of Ac-p65 and CD40, compared with the TNF- $\alpha$ group (Fig. 3L-N). To further affirm the above results, we silenced the expression of SIRT1 in IMCD cells. Treatment of IMCD cells with the SIRT1 inhibitors Ex527 $(1 \mu \mathrm{M})$ and sirtinol $(10 \mu \mathrm{M})$ or SIRT1 siRNA strikingly reduced the expression of SIRT1 (Fig. 3A, Fig. 4D). Then the IMCD cells were pretreated with Ex527 or sirtinol for $1 \mathrm{~h}$ or SIRT1 siRNA for $48 \mathrm{~h}$ prior to stimulation with TNF- $\alpha(20 \mu \mathrm{g} / \mathrm{L})$ for $24 \mathrm{~h}$. The results showed that Ex527 or sirtinol obviously promoted TNF- $\alpha$-induced CD40 and Ac-p65 expression in IMCD cells (Fig. 4AC). Moreover, knockdown of SIRT1 remarkably increased the expression CD40 mRNA and protein and Ac-p65 protein in TNF- $\alpha$-induced IMCD cells (Fig. 4E-G).

To examine whether NF- $\mathrm{kBp} 65$ was involved in the expression of CD40 in IMCD cells treated with TNF- $\alpha$, we silenced the expression of NF- $\mathrm{Bp} 65$. Treatment of IMCD cells with 

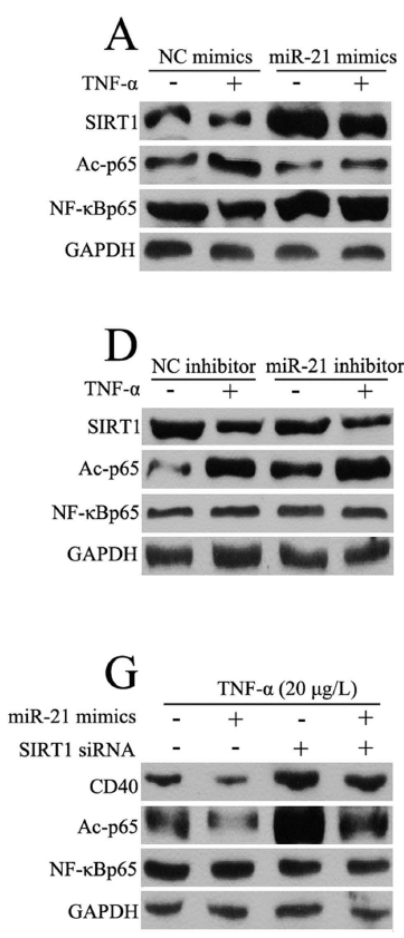
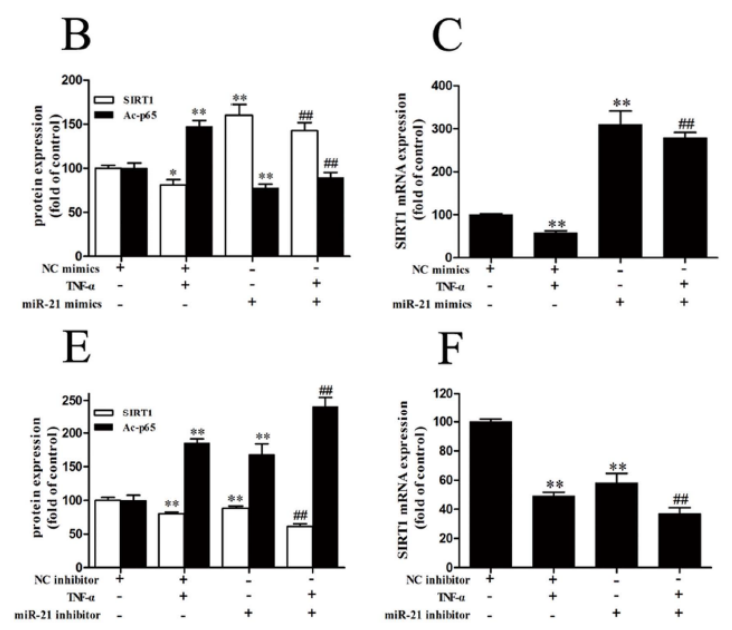

$\mathrm{H}$

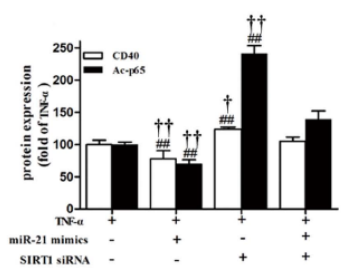

$\mathrm{F}$

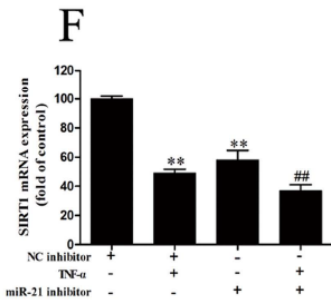

I

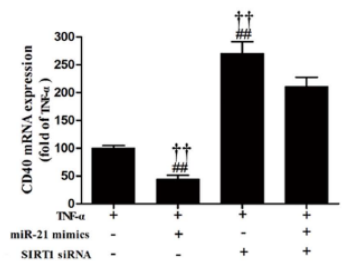

Fig. 6. miR-21 diminishes TNF- $\alpha$-induced CD40 expression through the SIRT1-NF- $\kappa$ B pathway in IMCD cells. (A-C) The IMCD cells transfected with miR-21 mimics were treated with TNF- $\alpha(20 \mu \mathrm{g} / \mathrm{L})$ for $24 \mathrm{~h}$, and the expression of SIRT1 mRNA and protein and Ac-p65 protein was examined. ${ }^{*} P<0.05$ and ${ }^{* *} P<0.01$ vs. NC mimics group; ${ }^{\# \#} P<0.01$ vs. NC mimics + TNF- $\alpha$ group. (D-F) The IMCD cells transfected with miR-21 inhibitor were treated with TNF- $\alpha(20 \mu \mathrm{g} / \mathrm{L})$ for $24 \mathrm{~h}$, and the expression of mRNA and protein and Ac-p65 protein was examined. ${ }^{* *} P<0.01$ vs. NC inhibitor group; ${ }^{\#} P<0.01$ vs. NC inhibitor + TNF- $\alpha$ group. (G-I) The SIRT1 knockdown cells were transfected with miR-21 mimics for $48 \mathrm{~h}$ and subsequently treated with TNF- $\alpha$ $(20 \mu \mathrm{g} / \mathrm{L})$ for $24 \mathrm{~h}$. The expression of CD40 mRNA and protein and Ac-p65 protein was examined. ${ }^{\# \# ~} P<0.01$ vs. TNF- $\alpha$ group; ${ }^{\dagger} P<0.05$ and ${ }^{\dagger+} P<0.01$ vs. SIRT1 siRNA + miR-21 mimics + TNF- $\alpha$ group. The results are expressed as the means \pm SD from triplicate experiments.

the NF- $\kappa$ B inhibitor PDTC or NF- $\kappa$ Bp65 siRNA strikingly decreased the expression of Ac-p65 (Fig. 5A and C). Then the IMCD cells were pretreated with PDTC for $1 \mathrm{~h}$ or NF- $\kappa B p 65$ siRNA for $48 \mathrm{~h}$ prior to stimulation with TNF- $\alpha(20 \mu \mathrm{g} / \mathrm{L})$ for $24 \mathrm{~h}$. The results showed that PDTC strikingly decreased the expression of CD40 mRNA and protein in IMCD cells compared with the TNF- $\alpha$ group (Fig. 5A and B). Knockdown of NF- $\mathrm{kBp} 65$ further supported the above results by decreasing the expression of CD40 compared with the TNF- $\alpha$ group (Fig. 5D and E).

To further confirm whether SIRT1 regulated TNF- $\alpha$-induced CD40 expression through the NF- $\kappa B$ pathway, the NF- $\kappa B p 65-k n o c k d o w n$ cells were pretreated with pcDNA3.1(+)SIRT1 for $48 \mathrm{~h}$ and then stimulated with TNF- $\alpha(20 \mu \mathrm{g} / \mathrm{L})$ for $24 \mathrm{~h}$. The results revealed that CD40 expression was significantly decreased in the combination (NF- $\kappa$ Bp65 siRNA and pcDNA3.1(+)-SIRT1) treatment group compared with the single treatment group in TNF$\alpha$-induced IMCD cells (Fig. 5F). These results imply that SIRT1 can regulate TNF- $\alpha$-induced CD40 expression in IMCD cells via suppression of NF- $\kappa B$ signalling.

miR-21 diminishes TNF- $\alpha$-induced CD40 expression through the SIRT1-NF- $\kappa B$ pathway in IMCD cells

To clarify the mechanism underlying miR-21-regulated CD40 expression in IMCD cells, the SIRT1 pathway was introduced. IMCD cells transfected with miR-21 mimics were treated 
with TNF- $\alpha(20 \mu \mathrm{g} / \mathrm{L})$ for $24 \mathrm{~h}$, and the expression of SIRT1 mRNA and protein and Ac-p65 protein was examined. The results showed that transfection with miR-21 mimics strikingly augmented the expression of SIRT1 mRNA and protein and impeded the expression of Acp65 protein (Fig. 6A-C). Consistently, an inhibitor of miR-21 significantly decreased the expression of SIRT1 mRNA and protein in IMCD cells stimulated with TNF- $\alpha$, concomitant with the increase in Ac-p65 protein (Fig. 6D-F). The results indicated that miR-21 can regulate the SIRT1-NF- $\kappa B$ pathway in IMCD cells stimulated with TNF- $\alpha$.

To further assess the correlation between the miR-21-regulated SIRT1 signalling pathway and CD40 expression in TNF- $\alpha$-induced IMCD cells, we inhibited the expression of SIRT1. The SIRT1-knockdown cells were pretreated with miR-21 mimics for $48 \mathrm{~h}$ and then stimulated with TNF- $\alpha(20 \mu \mathrm{g} / \mathrm{L})$ for $24 \mathrm{~h}$. The results revealed that transfection with miR21 mimics significantly decreased the expression of CD40 protein and mRNA and Ac-p65 protein in TNF- $\alpha$-induced IMCD cells, which was prominently attenuated by pretreatment with SIRT1 siRNA (Fig. 6G-I). Together, our data suggested that miR-21inhibited CD40 expression induced by TNF- $\alpha$ through SIRT1-NF- $\kappa B$ signalling in IMCD cells.

\section{Discussions}

It is widely accepted that dysfunctional miRNA expression, specifically the expression of miR-21, plays a role in the up-regulation of mechanisms responsible for the progression of kidney injury $[35,36]$. The renal expression level of miR-21 was significantly elevated during different phases of renal ischaemia-reperfusion injury [36, 37]. The present study indicated that TNF- $\alpha$ induced the expression level of miR-21 in IMCD cells in a concentration- and time-dependent manner. Recently, miRs have drawn more attention due to their prominent function in inflammatory processes in renal disease. Sheedy et al. have reported that transfection with a miR-21 precursor into human peripheral blood mononuclear cells treated with LPS promotes the production of anti-inflammatory factor IL-10 [38]. We found that mimics of miR-21 decreased the expression of CD40 mRNA and protein, whereas an inhibitor of miR-21 increased the expression of CD40 mRNA and protein in IMCD cells exposed to TNF- $\alpha$, suggesting that miR-21 may regulate CD40 expression in IMCD cells. Nevertheless, it has been reported that suppression of miR-21 causes a reduction in the proinflammatory cytokine TNF- $\alpha$ and monocyte chemoattractant protein-1 in a mouse model of type 2 diabetes [38]. Another study revealed that overexpression of miR-21 resulted in upregulation of TNF- $\alpha$ and interferon- $\gamma$ in B6 T cells [39]. Therefore, these results indicate that miR-21 may play different roles in various types of cells and tissues in response to a variety of stimuli.

Preclinical and clinical studies have shown that the pro-inflammatory cytokine CD40 plays a crucial role in the onset and maintenance of the inflammatory reaction [14], and activation of CD40 contributes to renal inflammation and injury in vivo and in vitro [40,41]. In the present study, TNF- $\alpha$ significantly increased CD40 expression at mRNA and protein levels in IMCD cells in a time- and concentration-dependent manner. In agreement with our results, CD40 expression was up-regulated in renal proximal tubular epithelial cells and human renal mesangial cells in response to transforming growth factor-beta (TGF- $\beta$ ) and soluble monosodium urate, respectively $[42,43]$. These results show that the increased expression of CD40 appears to trigger inflammation in renal tissue in response to inducers such as inflammatory stimuli and TGF- $\beta$, and then aggravates the inflammatory state within renal tissue. In addition, our previous studies have reported a functional link between SIRT1 activity and CD40 expression in CRL-1730 endothelial cells and 3T3-L1 adipocytes [19, 20]. In these findings, SIRT1 exerts its inhibitory effects on CD40 expression in TNF- $\alpha$-induced IMCD cells by deacetylating the RelA/p65 subunit of NF- $\kappa B$ at lysine 310, a critical site for $\mathrm{NF}-\kappa \mathrm{B}$ activation. In accordance with the above results, the present study provided evidence that the expression levels of CD40 and the p65 subunit were downregulated by activating SIRT1 and that these effects were reversed by inhibiting SIRT1 activity, suggesting that the anti-CD40 effect of SIRT1 is attributable, at least in part, to inhibition of the NF- $\kappa B$ pathway. 
Studies have highlighted the critical role of miRs in the progression of renal disease through regulation of target gene expression $[44,45]$, and SIRT1 was shown to be regulated by miRs $[32,33,46,47]$. It has been revealed that miR-21 can protect the kidney against ischaemia-reperfusion injury by inhibiting the inflammatory response and apoptosis, which is one of the mechanisms involved in the protective effect of renal ischaemic preconditioning in vivo and in vitro $[48,49]$. Our present study demonstrated that miR-21 overexpression strikingly augmented the expression of SIRT1 protein and mRNA, while inhibition of miR-21 significantly decreased the expression of SIRT1 protein and mRNA in IMCD cells treated with TNF- $\alpha$, implying that miR-21 may regulate the expression of SIRT1 in IMCD cells. In addition, it has been reported that transfection of a miR-21 precursor into human peripheral blood mononuclear cells treated with LPS blocks NF- $\kappa B$ activity [38]. A recent study also revealed that transfection with miR-21 mimics strikingly impeded the intra-nuclear NF- $\kappa B$ p65 levels in LPS-induced macrophages [31]. Our results found that miR-21 overexpression obviously impeded the expression of Ac-p65 protein, whereas inhibition of miR-21 increased TNF$\alpha$-induced expression of Ac-p65 in IMCD cells. Our data suggest that miR-21 can inhibit the activation of NF- $\mathrm{BB}$ in IMCD cells. Moreover, it has been demonstrated that inhibition of the miR-34a enhances SIRT1 signalling and then decreases acetylation of NF- $\mathrm{kBp} 65$ in macrophages [50]. A recent study found that reduced miR-23b-3p expression inhibited acetylation of NF- $\mathrm{KB}$ expression by rescuing SIRT1 expression in high glucose-induced diabetic retinopathy [51]. The present study showed that knockdown of SIRT1 abolished the inhibitory effect of miR-21 on the TNF- $\alpha$-induced the expression of Ac-p65 in IMCD cells, indicating that miR-21 inhibits the activation of NF- $\kappa B$ in TNF- $\alpha$-induced IMCD cells via SIRT1 signalling. This seems to be consistent with the results of the previous studies. However, there is much to learn about the correlation between the miR-21-regulated SIRT1NF- $\kappa B$ pathway and CD40 expression in TNF- $\alpha$-induced IMCD cells. Accordingly, SIRT1 siRNA was applied to further clarify whether SIRT1 was involved in the CD40 inhibitory effects of miR-21. We found that knockdown of SIRT1 diminished the inhibitory effect of miR-21 on TNF- $\alpha$-induced CD40 expression in IMCD cells, suggesting that SIRT1 is associated with the inhibitory effects of miR-21 on TNF- $\alpha$-induced CD40 expression. Taken together, these findings support the notion that miR-21 inhibits CD40 expression in IMCD cells through a SIRT1-dependent signalling pathway. However, the mechanism involved in miR-21 regulation of SIRT1-NF- $\kappa B$ is still unclear, and needs to be explored in our next study.

In conclusion, our results indicate that miR-21 can regulate TNF- $\alpha$-induced inflammatory responses in IMCD cells through the SIRT1-NF-кB pathway. Accordingly, our research provides valuable insight into understanding the anti-inflammatory effect of miR-21 and suggests a promising therapeutic prospect, through miR-21 overexpression, for prevention and treatment of damage from inflammation-related diseases.

\section{Acknowledgments}

This study was supported by the National Natural Science Foundation of China (No. 31300978,31371199 ), the Science and Technology Program of Hebei Province of China (No. 12277652), and the Outstanding Youth fund of Higher Education of Hebei Province of China (No. YQ2014004).

\section{Disclosure Statement}

The authors have no conflicts of interest to declare.

\section{References}

1 Chung S, Yao H, Caito S, Hwang JW, Arunachalam G, Rahman I: Regulation of SIRT1 in cellular functions: role of polyphenols. Arch Biochem Biophys 2010;501:79-90.

2 Hwang JW, Yao H, Caito S, Sundar IK, Rahman I: Redox regulation of SIRT1 in inflammation and cellular senescence. Free Radic Biol Med 2013;61:95-110. 


\section{Cellular Physiology Cell Physiol Biochem 2017;41:124-136

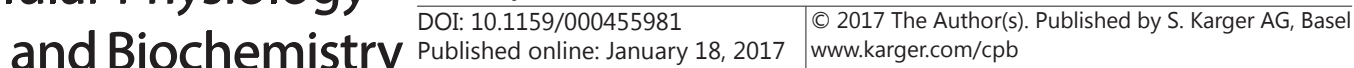

Lin et al.: miR-21 Regulates CD40 Expression via SIRT1-NF-KB Pathway

- 3 Polak-Jonkisz D, Laszki-Szcząchor K, Rehan L, Pilecki W, Filipowski H, Sobieszczańska M: Nephroprotective action of sirtuin 1 (SIRT1). J Physiol Biochem 2013;69:957-961.

-4 Kong L, Wu H, Zhou W, Luo M, Tan Y, Miao L, Cai L: Sirtuin 1: A Target for Kidney Diseases. Mol Med 2015;21:87-97.

-5 Dong YJ, Liu N, Xiao Z, Sun T, Wu SH, Sun WX, Xu ZG, Yuan H: Renal protective effect of sirtuin 1. J Diabetes Res 2014;2014:843786.

-6 Hasegawa K, Wakino S, Yoshioka K, Tatematsu S, Hara Y, Minakuchi H, Sueyasu K, Washida N, Tokuyama H, Tzukerman M, Skorecki K, Hayashi K, Itoh H: Kidney-specific overexpression of Sirt1 protects against acute kidney injury by retaining peroxisome function. J Biol Chem 2010;285:13045-13056.

7 Gao R, Chen J, Hu Y, Li Z, Wang S, Shetty S, Fu J: Sirt1 deletion leads to enhanced inflammation and aggravates endotoxin-induced acute kidney injury. PLoS One 2014;9:e98909.

-8 Rabb H, Griffin MD, McKay DB, Swaminathan S, Pickkers P, Rosner MH, Kellum JA, Ronco C: Acute Dialysis Quality Initiative Consensus XIII Work Group: Inflammation in AKI: Current Understanding, Key Questions, and Knowledge Gaps. J Am Soc Nephrol 2016;27:371-379.

\9 Nentwig A, Schweighauser A, Maissen-Villiger C, Bruckmaier RM, Zurbriggen A, van Dorland HA, Francey T: Assessment of the expression of biomarkers of uremic inflammation in dogs with renal disease. Am J Vet Res 2016;77:218-224.

10 Kwon TH, Frokiaer J, Fernandez-Llama P, Knepper MA, Nielsen S: Reduced abundance of aquaporins in rats with bilateral ischemia-induced acute renal failure: prevention by alpha-MSH. Am J Physiol 1999;277:F413-427.

11 Bonventre JV, Zuk A: Ischemic acute renal failure: an inflammatory disease? Kidney Int 2004;66:480-485.

12 Cui WY, Tian AY, Bai T: Protective effects of propofol on endotoxemia-induced acute kidney injury in rats. Clin Exp Pharmacol Physiol 2011;38:747-754.

13 Hocherl K, Schmidt C, Kurt B, Bucher M: Inhibition of NF-kappaB ameliorates sepsis-induced downregulation of aquaporin-2/V2 receptor expression and acute renal failure in vivo. Am J Physiol Renal Physiol 2010;298:F196-204.

14 Rizvi M, Pathak D, Freedman JE, Chakrabarti S: CD40-CD40 ligand interactions in oxidative stress, inflammation and vascular disease. Trends Mol Med 2008;14:530-538.

15 Laxmanan S, Datta D, Geehan C, Briscoe DM, Pal S: CD40: a mediator of pro- and anti-inflammatory signals in renal tubular epithelial cells. J Am Soc Nephrol 2005;16:2714-2723.

-16 Li H, Nord EP: IL-8 amplifies CD40/CD154-mediated ICAM-1 production via the CXCR-1 receptor and p38MAPK pathway in human renal proximal tubule cells. Am J Physiol Renal Physiol 2009;296:F438-445.

17 Pontrelli P, Ursi M, Ranieri E, Capobianco C, Schena FP, Gesualdo L, Grandaliano G: CD40L proinflammatory and profibrotic effects on proximal tubular epithelial cells: role of NF-kappaB and lyn. J Am Soc Nephrol 2006;17:627-636.

18 Salminen A, Kauppinen A, Suuronen T, Kaarniranta K: SIRT1 longevity factor suppresses NF-kappaB -driven immune responses: regulation of aging via NF-kappaB acetylation? Bioessays 2008;30:939-942.

19 Lin QQ, Yan CF, Lin R, Zhang JY, Wang WR, Yang LN, Zhang KF: SIRT1 regulates TNF-alpha-induced expression of CD40 in 3T3-L1 adipocytes via NF-kappaB pathway. Cytokine 2012;60:447-455.

20 Yang L, Zhang J, Yan C, Zhou J, Lin R, Lin Q, Wang W, Zhang K, Yang G, Bian X, Zeng A: SIRT1 regulates CD40 expression induced by TNF-alpha via NF-kB pathway in endothelial cells. Cell Physiol Biochem 2012;30:1287-1298.

21 Tone M, Tone Y, Babik JM, Lin CY, Waldmann H: The role of Sp1 and NF-kappa B in regulating CD40 gene expression. J Biol Chem 2002;277:8890-8897.

22 Krol J, Loedige I, Filipowicz W: The widespread regulation of microRNA biogenesis, function and decay. Nat Rev Genet 2010;11:597-610.

-23 Bhatt K, Mi QS, Dong Z: microRNAs in kidneys: biogenesis, regulation, and pathophysiological roles. Am J Physiol Renal Physiol 2011;300:F602-610.

-24 Ranganathan P, Jayakumar C, Tang Y, Park KM, Teoh JP, Su H, Li J, Kim IM, Ramesh G: MicroRNA-150 deletion in mice protects kidney from myocardial infarction-induced acute kidney injury. Am J Physiol Renal Physiol 2015;309:F551-558.

25 Jia P, Teng J, Zou J, Fang Y, Wu X, Liang M, Ding X: Xenon Protects Against Septic Acute Kidney Injury via miR-21 Target Signaling Pathway. Crit Care Med 2015;43:e250-259.

-26 Wu C, Gong Y, Yuan J, Zhang W, Zhao G, Li H, Sun A; KaiHu, Zou Y, Ge J: microRNA-181a represses ox-LDLstimulated inflammatory response in dendritic cell by targeting c-Fos. J Lipid Res 2012;53:2355-2363.

27 Hua C, Sun L, Yang Y, Tan R, Hou Y: Mechanisms of CpG-induced CD40 expression on murine bone marrowderived dendritic cells. Autoimmunity 2013;46:177-187. 


\section{Cellular Physiology Cell Physiol Biochem 2017;41:124-136

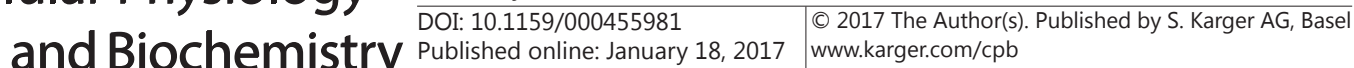

Lin et al.: miR-21 Regulates CD40 Expression via SIRT1-NF-KB Pathway

28 Li YF, Jing Y, Hao J, Frankfort NC, Zhou X, Shen B, Liu X, Wang L, Li R: MicroRNA-21 in the pathogenesis of acute kidney injury. Protein Cell 2013;4:813-819.

29 Liu X, Hong Q Wang Z, Yu Y, Zou X, Xu L: MiR-21 inhibits autophagy by targeting Rab11a in renal ischemia/ reperfusion. Exp Cell Res 2015;338:64-69.

-30 Liu XJ, Hong Q Wang Z, Yu YY, Zou X, Xu LH: MicroRNA21 promotes interstitial fibrosis via targeting DDAH1: a potential role in renal fibrosis. Mol Cell Biochem 2016;411:181-189.

- 31 Feng J, Li A, Deng J, Yang Y, Dang L, Ye Y, Li Y, Zhang W: miR-21 attenuates lipopolysaccharide-induced lipid accumulation and inflammatory response: potential role in cerebrovascular disease. Lipids Health Dis 2014;13:27.

-32 Choi SE, Kemper JK: Regulation of SIRT1 by microRNAs. Mol Cells 2013; 36:385-392.

33 Yamakuchi M: MicroRNA Regulation of SIRT1. Front Physiol 2012;3:68.

-34 Faust D, Geelhaar A, Eisermann B, Eichhorst J, Wiesner B, Rosenthal W, Klussmann E: Culturing primary rat inner medullary collecting duct cells. J Vis Exp DOI:10.3791/50366.

- 35 Saikumar J, Hoffmann D, Kim TM, Gonzalez VR, Zhang Q Goering PL, Brown RP, Bijol V, Park PJ, Waikar SS, Vaidya VS: Expression, circulation, and excretion profile of microRNA-21, -155, and -18a following acute kidney injury. Toxicol Sci 2012;129:256-267.

-36 Xu X, Kriegel AJ, Liu Y, Usa K, Mladinov D, Liu H, Fang Y, Ding X, Liang M: Delayed ischemic preconditioning contributes to renal protection by upregulation of miR-21. Kidney Int 2012;82:1167-1175.

37 Ma L, Wu K, Liu K, Gu S, Wang Y, Xu Z, Yu X, Meng J: Changes of miRNA-17-5p, miRNA-21 and miRNA-106a level during rat kidney ischemia-reperfusion injury. Zhonghua Yi Xue Za Zhi 2015;95:1488-1492.

-38 Sheedy FJ, Palsson-McDermott E, Hennessy EJ, Martin C, O'Leary JJ, Ruan Q, Johnson DS, Chen Y, O'Neill LA: Negative regulation of TLR4 via targeting of the proinflammatory tumor suppressor PDCD4 by the microRNA miR-21. Nat Immunol 2010;11:141-147.

-39 Ando Y, Yang GX, Kenny TP, Kawata K, Zhang W, Huang W, Leung PS, Lian ZX, Okazaki K, Ansari AA, He XS, Invernizzi P, Ridgway WM, Lu Q, Gershwin ME: Overexpression of microRNA-21 is associated with elevated pro-inflammatory cytokines in dominant-negative TGF-beta receptor type II mouse. J Autoimmun 2013;41:111-119.

40 Donner AJ, Yeh ST, Hung G, Graham MJ, Crooke RM, Mullick AE: CD40 Generation 2.5 Antisense Oligonucleotide Treatment Attenuates Doxorubicin-induced Nephropathy and Kidney Inflammation. Mol Ther Nucleic Acids 2015;4:e265.

-41 de Ramon L, Ripoll E, Merino A, Lúcia M, Aran JM, Pérez-Rentero S, Lloberas N, Cruzado JM, Grinyó JM, Torras J: CD154-CD40 T-cell co-stimulation pathway is a key mechanism in kidney ischemia-reperfusion injury. Kidney Int 2015;88:538-549.

42 Starke A, Wuthrich RP, Waeckerle-Men Y: TGF-beta treatment modulates PD-L1 and CD40 expression in proximal renal tubular epithelial cells and enhances CD8 cytotoxic T-cell responses. Nephron Exp Nephrol 2007;107:e22-29.

43 Xiao J, Fu C, Zhang X, Zhu D, Chen W, Lu Y, Ye Z: Soluble monosodium urate, but not its crystal, induces toll like receptor 4-dependent immune activation in renal mesangial cells. Mol Immunol 2015;66:310-318.

44 Chung AC: microRNAs in Diabetic Kidney Disease. Adv Exp Med Biol 2015;888:253-269.

45 Gomez IG, Grafals M, Portilla D, Duffield JS: MicroRNAs as potential therapeutic targets in kidney disease. J Formos Med Assoc 2013;112:237-243.

-46 Qin W, Xie W, Yang X, Xia N, Yang K: Inhibiting microRNA-449 Attenuates Cisplatin-Induced Injury in NRK52E Cells Possibly via Regulating the SIRT1/P53/BAX Pathway. Med Sci Monit 2016;22:818-823.

47 McCubbrey AL, Nelson JD, Stolberg VR, Blakely PK, McCloskey L, Janssen WJ, Freeman CM, Curtis JL: MicroRNA-34a Negatively Regulates Efferocytosis by Tissue Macrophages in Part via SIRT1. J Immunol 2016;196:1366-1375.

48 Wei Q Mi QS, Dong Z: The regulation and function of microRNAs in kidney diseases. IUBMB Life 2013;65:602-614.

-49 Zhang W, Shu L: Upregulation of miR-21 by Ghrelin Ameliorates Ischemia/Reperfusion-Induced Acute Kidney Injury by Inhibiting Inflammation and Cell Apoptosis. DNA Cell Biol 2016;35:417-425.

-50 Kim HJ, Joe Y, Yu JK, Chen Y, Jeong SO, Mani N, Cho GJ, Pae HO, Ryter SW, Chung HT: Carbon monoxide protects against hepatic ischemia/reperfusion injury by modulating the miR-34a/SIRT1 pathway. Biochim Biophys Acta 2015;1852:1550-1559.

51 Zhao S, Li T, Li J, Lu Q, Han C, Wang N, Qiu Q1, Cao H, Xu X, Chen H, Zheng Z: miR-23b-3p induces the cellular metabolic memory of high glucose in diabetic retinopathy through a SIRT1-dependent signalling pathway. Diabetologia 2016;59:644-654. 